\title{
Avaliação da dispersão de efluente líquido de refinaria de petróleo
}

\section{Evaluation of the dispersion of oil refinery liquid effluent}

\begin{abstract}
Adriano Pinto Mariano
Engenheiro Químico pela Universidade Estadual de Campinas (UNICAMP). Doutor em Geociências e Meio Ambiente pelo Instituto de Geociências e Ciências Exatas da Universidade Estadual Paulista "Júlio Mesquita Filho" (IGCE/UNESP). Pesquisador na Faculdade de Engenharia Química da UNICAMP, e no Departamento de Bioquímica e Microbiologia do Instituto de Biociências da UNESP (Campus de Rio Claro)

\section{Ariovaldo José da Silva}

Graduado em Tecnologia Sanitária, Modalidade Saneamento, pela UNICAMP. Doutor em Engenharia Hidráulica e Saneamento pela Universidade de São Paulo (USP)
\end{abstract}

\section{Valdenilson José Alves de Oliveira}

Biólogo pela Fundação Herminio Hometto, Uniararas. Colaborador do Departamento de Bioquímica e Microbiologia do Instituto de Biociências da UNESP (Campus de Rio Claro)

\section{Dejanira de Franceschi de Angelis}

Bióloga pela UNESP. Doutora em Ciências pela UNESP. Livre-docente do Departamento de Bioquímica e Microbiologia do Instituto de Biociências da UNESP (Campus de Rio Claro)

\section{Resumo}

Neste trabalho são apresentadas duas técnicas para a avaliação da dispersão, num corpo d'água receptor, do efluente líquido de uma refinaria de petróleo. Assim, a pluma de dispersão foi caracterizada por medidas em campo de condutividade elétrica e por simulação computacional (simulador Cormix). Como caso de estudo, escolheu-se uma refinaria de petróleo cujo efluente é lançado no rio Atibaia (Paulínia/SP). O comportamento do efluente foi avaliado em um trecho de $1000 \mathrm{~m}$ após o ponto de lançamento. Os resultados demonstraram que a medição da condutividade elétrica é uma técnica adequada para a avaliação da dispersão de efluentes líquidos de refinaria de petróleo, pois apresentam alta condutividade elétrica e, com isso, há um forte contraste entre os valores do efluente e do rio. Além disso, outros parâmetros de qualidade da água do rio seguiram comportamento de dispersão semelhante ao da condutividade. A pluma de dispersão gerada pelo simulador computacional apresentou uma elevada concordância com os dados obtidos em campo. Nesse sentido, a simulação computacional pode ser uma ferramenta útil para a avaliação da dispersão do efluente considerando-se cenários hipotéticos, e para projetos de emissários.

Palavras-chave: pluma de dispersão; efluente líquido; condutividade elétrica; simulação da dispersão.

\section{Abstract}

In this paper, two techniques to evaluate the dispersion of the effluent of an oil refinery are presented. Thus, the dispersion plume was characterized by field measurements of electrical conductivity and by computational simulation (Cormix simulator). An oil refinery whose effluent is discharged on the Atibaia river (Paulínia/SP) is taken as study case. The behavior of the effluent was evaluated until $1000 \mathrm{~m}$ after the discharge. The results show that the measurement of electrical conductivity is a suitable technique to evaluate the dispersion of oil refinery wastewaters, since they have high conductivity and for this reason there is a strong contrast between the values of the wastewater and the ambient background. Furthermore, other water quality parameters had a dispersion behavior similar to that shown by the conductivity. The dispersion plume generated by the computational simulator showed high concordance with the field data. In this manner, computational simulation can be a useful tool to evaluate the dispersion of discharges considering hypothetic scenarios, as well as to design the discharge channel.

Keywords: dispersion plume; wastewater; electrical conductivity; dispersion simulation. 


\section{Introdução}

Durante o processo de refino do petróleo, são utilizados em média 246 a 340 L de água por barril de óleo cru, gerando uma quantidade de água residuária em torno de 0,4 a 1,6 vezes o volume de óleo processado (SANTAELLA et al, 2009). Considerando que, em 2007, nas 14 refinarias nacionais foram refinados 323,8 $\mathrm{mil} \mathrm{m} 3 /$ dia (ANP, 2008), o volume de água residuária gerado por essa atividade é muito significativo e, por isso, existe a necessidade de estudos relativos ao entendimento do comportamento e impacto dos efluentes líquidos dessa atividade lançados nos corpos d'água.

No âmbito federal, a classificação dos corpos de água e diretrizes ambientais para o seu enquadramento, bem como o estabelecimento das condições e padrões de lançamento de efluentes, são regulamentados pela Resolução n. 357 de março de 2005 do Conselho Nacional de Meio Ambiente (CONAMA). Nesta resolução, a zona de mistura é definida como a região do corpo receptor onde ocorre a diluição inicial de um efluente. Pode-se ler no artigo 33:

\section{[...] a extensão e as concentrações de substâncias na zona de mis-} tura deverão ser objeto de estudo, nos termos determinados pelo órgão ambiental competente, às expensas do empreendedor responsável pelo lançamento.

O estudo da zona de mistura permite compreender o fluxo, a dispersão e a decomposição dos compostos presentes nos efluentes lançados em canais naturais. Este conhecimento é de extrema importância para a solução de vários problemas presentes no descarte de efluentes industriais nos rios. Dentre estes problemas, destaca-se a escolha do melhor ponto de emissão de um efluente industrial, a determinação da distância necessária para a dispersão e mistura deste efluente e a distância para que ocorra a degradação das substâncias biodegradáveis presentes neste lançamento (MACHADO et al, 2008).

O fenômeno de dispersão de efluentes industriais em rios é mostrado esquematicamente na Figura 1. De acordo com esta figura, o efluente é lançado com uma dada vazão na lateral do rio e, à medida que percorre o leito do rio, a pluma de efluente formada vai se expandindo ao longo da zona de mistura, de comprimento LD, até atingir uma mistura completa, onde não há mais dispersão significativa. A partir deste ponto, apenas as reações de decomposição da substância em estudo, caso seja um componente degenerativo, devem ser levadas em consideração.

A análise da zona de mistura de efluentes é igualmente importante para a determinação da capacidade de suporte de carga do corpo de água receptor exigida nos processos de licenciamento ou de sua renovação no caso de empreendimento de impacto significativo. Além disso, ainda de acordo com o artigo 33 da resolução 357:

na zona de mistura de efluentes, o órgão ambiental competente poderá autorizar, levando em conta o tipo de substância, valores em desacordo com os estabelecidos para a respectiva classe de enquadramento, desde que não comprometam os usos previstos para o corpo de água.

Sendo assim, seguindo a determinação da Resolução 357, todo empreendedor que venha lançar efluentes em um corpo d'água terá que realizar estudos semelhantes aos aqui apresentados. Com isso, este trabalho objetivou avaliar a aplicabilidade de duas técnicas para a determinação da zona de mistura do efluente líquido de uma refinaria de petróleo. Utilizando dados de campo (medidas de condutividade elétrica) e o simulador comercial Cormix, foi possível obter a geometria da pluma de dispersão do efluente, bem como a dimensão da zona de mistura.

Cormix é um simulador comercial que possui resultados rápidos, é de fácil utilização e recomendado pelo Órgão de Proteção Ambiental Americano (USEPA) (DONEKER; JIRKA, 2001), que vem sendo utilizado como sistema de suporte para análises de impactos ambientais em zonas de misturas resultantes de fontes de descartes pontuais. Jones et al (2007) apresenta uma lista de exemplos de casos nos quais o simulador foi empregado, e maiores detalhes a respeito de sua base científica podem ser encontrados em Doneker e Jirka (2001) e Doneker et al (2007). Contudo, cabe ressaltar que existem outros simuladores, como o Fluent, Delft3D e o CFX, cujos exemplos de uso podem ser encontrados em Xia e Lam (2004), Pun (2006) e Baud et al (2005), respectivamente. Além disso, há no Brasil um grupo de pesquisa da Faculdade de Engenharia Química da Unicamp que vem trabalhando com o desenvolvimento desses simuladores (MACHADO et al, 2008).

\section{Material e métodos}

\section{Área de estudo}

O comportamento do efluente da refinaria de petróleo foi avaliado em um trecho de 1000 m do Rio Atibaia (Paulínia, SP) após o ponto de lançamento (Figura 2). O emissário é um canal perpendicular à margem direita do rio com aproximadamente $4 \mathrm{~m}$ de largura e 0,50 m de profundidade. Na Tabela 1, são apresentadas as características do rio Atibaia e do efluente lançado pela refinaria. Como a vazão do rio não foi determinada na data da amostragem, assumiu-se o valor determinado anteriormente por Machado et al (2008). É importante mencionar que esses valores estão sujeitos a alterações em virtude de variações climáticas e do processo produtivo da refinaria.

\section{Determinação da zona de mistura}

Para a determinação da extensão da zona de mistura, foram utilizadas medidas de campo realizadas em 25 de agosto de 2008. O 
parâmetro utilizado como traçador foi a condutividade elétrica, pois, devido ao processo de dessalgação do petróleo, o efluente de refinarias é caracterizado pelo alto teor de cloretos e, além disso, o rio Atibaia tem em relação ao efluente uma concentração muito menor.

A condutividade elétrica foi medida consecutivamente em diferentes pontos da superfície do rio (10 $\mathrm{cm}$ de profundidade) com o equipamento de campo YSI 3000 TLC, segundo a malha de distribuição de pontos apresentada na seção Resultados e Discussão. Mapas de linhas de isoconcentrações foram obtidos com o programa Surfer 8. Medidas em perfil não foram realizadas.

A geometria da pluma de dispersão e a extensão da zona de mistura obtidos em campo foram comparadas a resultados gerados pelo simulador Cormix 5.0G. Compõem este simulador três módulos destinados a representar lançamentos em superfície e submersos. O módulo utilizado no presente trabalho foi o Cormix3, destinado a análises de despejos em superfícies de rios, lagos e estuários. Os dados de entrada para o simulador dividem-se em dois grupos: i) caracterização do rio (dimensões do canal retangular, vazão, temperatura, concentração do poluente e outros); ii) caracterização do emissário (geometria, vazão, temperatura, concentração do poluente, ângulo de contato com o rio e outros). Maiores detalhes a respeito dos dados necessários para a realização da simulação podem ser encontrados em Doneker et al (2007).

Durante o período entre 1 de agosto de 2007 e 28 de maio de 2008, foram realizadas 18 coletas de dados (medidas de 16 parâmetros físicos e químicos, incluindo a condutividade) quinzenais em três pontos de amostragem do rio (amostras compostas ao longo da seção transversal da direção do fluxo do rio) localizados à montante do emissário (20 m) e à jusante (550 e 850 m), e também amostragem do efluente. As análises foram realizadas de acordo com metodologias descritas em APHA (1998).

\section{Resultados e discussão}

A Figura 3 mostra a pluma de dispersão na região próxima ao emissário. Pela diferença de colorações, é possível notar que o efluente, ao atingir o rio, forma uma pluma que é rapidamente defletida aderindo-se à margem. Este comportamento da pluma na zona próxima ao ponto de lançamento é fortemente determinado pela geometria do emissário e o seu ângulo de contato com o rio (DONEKER et al, 2007). Após aproximadamente $10 \mathrm{~m}$ do lançamento, não foi mais possível visualizar a pluma.

Além do método visual, a geometria da pluma também foi determinada pelas medidas de condutividade elétrica realizadas no local (Figura 4). Como a condutividade elétrica é mais elevada no efluente do que no rio à montante do emissário, há um contraste definido entre as medidas efetuadas na região do rio onde o efluente está presente e aquelas feitas em áreas não alcançadas pelo efluente, assim demarcando os limites da pluma de dispersão.

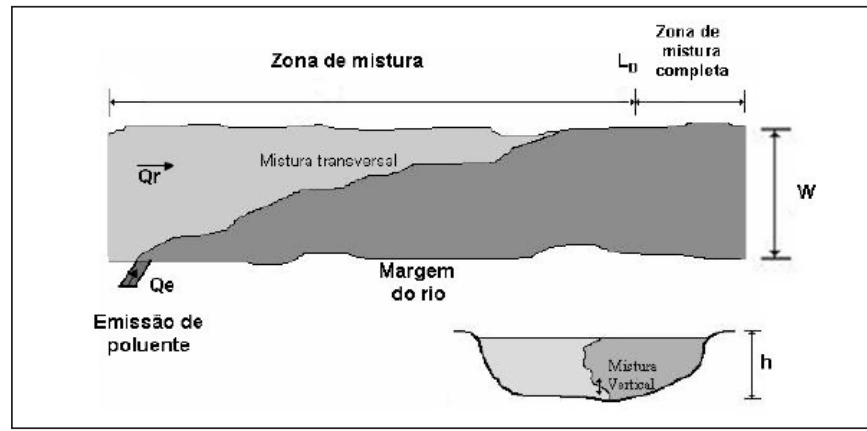

Figura 1 - Representação esquemática da zona de mistura (Machado, 2006)

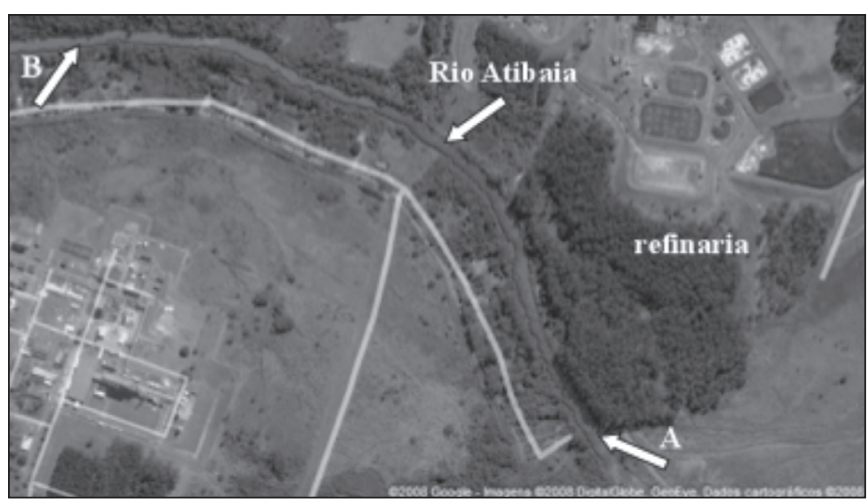

Figura 2 - Imagem de satélite da área de estudo. A seta A indica o ponto de lançamento do efluente da refinaria no rio Atibaia. A seta B indica 0 final do trecho de $1000 \mathrm{~m}$ analisado

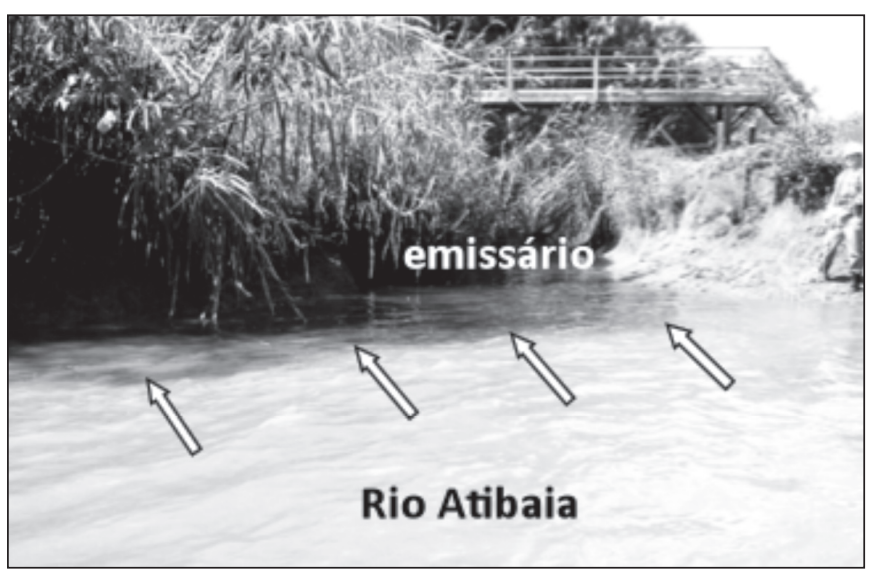

Figura 3 - Pluma de dispersão do efluente industrial na região próxima ao emissário. As setas demarcam os limites da pluma

Tabela 1 - Características do rio Atibaia e do efluente lançado pela refinaria Rio Atibaia

\begin{tabular}{lc} 
Vazão $\left(\mathrm{m}^{3} / \mathrm{s}\right)$ & $10,8^{*}$ \\
\hline Largura média $(\mathrm{m})$ & 29,0 \\
\hline Profundidade média $(\mathrm{m})$ & 1,50 \\
\hline Temperatura $\left({ }^{\circ} \mathrm{C}\right)$ & 21,5 \\
Condutividade $(\mu \mathrm{S} / \mathrm{cm})$ & 340 \\
Efluente & \\
Vazão $\left(\mathrm{m}^{3} / \mathrm{s}\right)$ & 0,13 \\
Temperatura $\left({ }^{\circ} \mathrm{C}\right)$ & 28,2 \\
\hline Condutividade $(\mu \mathrm{S} / \mathrm{cm})$ & 2260 \\
\hline
\end{tabular}

*Valor determinado por Machado et al. (2008) 
A utilização da condutividade elétrica para a determinação de zonas de mistura de efluentes de refinarias é bastante apropriada porque esses efluentes são caracterizados pela alta quantidade de sais dissolvidos, em particular os cloretos. As medidas deste parâmetro são efetuadas rapidamente em campo, não havendo a necessidade de transporte de amostras e análises em laboratório, o que despenderia tempo e recursos financeiros adicionais. Além disso, este parâmetro pode ser considerado bastante conservativo, ou seja, as variações de concentrações são decorrentes apenas de fenômenos de transferência de massa, predominando os efeitos convectivos em relação aos difusivos. Como em rios a convecção pode ser considerada o principal mecanismo de dispersão, pode-se admitir que todos os outros componentes solúveis do efluente são transportados da mesma maneira.

Além da caracterização da pluma na zona próxima ao lançamento, medidas de condutividade elétrica realizadas em um trecho de $1000 \mathrm{~m}$ após o lançamento do efluente determinaram a geometria nessa extensão (Figura 5). A adesão da pluma à margem do

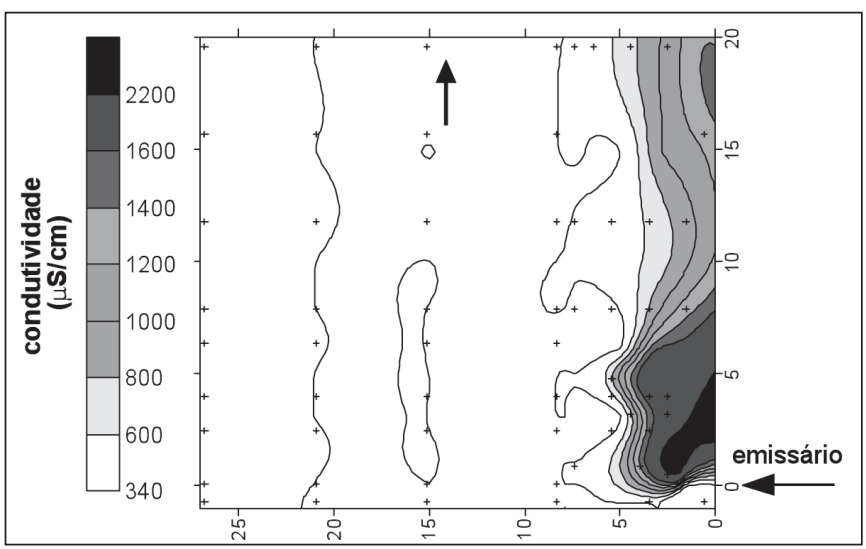

Figura 4 - Pluma de dispersão do efluente industrial determinada pelas medidas de condutividade elétrica na região próxima ao emissário (20 m). 0 símbolo + indica os pontos de amostragem

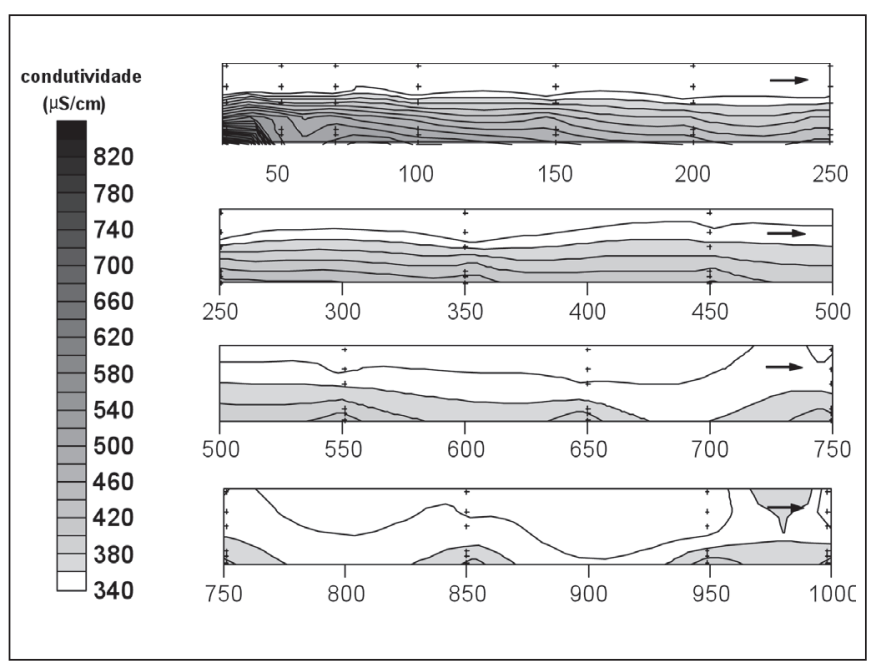

Figura 5 - Pluma de dispersão do efluente industrial determinada pelas medidas de condutividade elétrica em um trecho de $1000 \mathrm{~m}$ após 0 lançamento. 0 símbolo + indica os pontos de amostragem emissário dificulta a sua dispersão devido à menor velocidade da água nessa região. Com isso, nesse trecho a pluma concentra-se na margem, ocorrendo uma lenta dispersão. A Figura 6 mostra as medidas de condutividade elétrica ao longo de diferentes seções distanciadas $0 ; 3 ; 5 ; 15 ; 21$ e 29 m em relação à margem de lançamento. De acordo com esses valores, até $450 \mathrm{~m}$ após o lançamento, a pluma concentrou-se a uma distância de aproximadamente $5 \mathrm{~m}$ da margem, migrando até $15 \mathrm{~m}$ (a metade da largura do rio) durante o trecho subsequente. Na última seção amostrada (1000 m), os valores da condutividade na margem do lançamento $(0 \mathrm{~m})$ e na margem oposta (29 m) eram, respectivamente, 380 e $340 \mu \mathrm{S} / \mathrm{cm}$, uma diferença de $11,8 \%$. Portanto, após um percurso de $1000 \mathrm{~m}$, não ocorreu a total diluição do efluente no rio. Medidas não foram realizadas após esse trecho em função da presença de pedras no leito do rio que impedem a passagem do barco. As pedras aumentam o nível de turbulência, assim nessa região é esperada uma intensificação no processo de homogeneização das águas.

Durante o período entre 1 de agosto de 2007 e 28 de maio de 2008, foram realizadas 18 coletas de dados (16 parâmetros físicos e químicos foram analisados, incluindo medidas de condutividade) quinzenais em três pontos de amostragem no rio localizados à montante do emissário (20 m) e à jusante (550 e 850 m), e também amostragem do efluente. Estes dados são apresentados na Figura 7. Observou-se que os valores de condutividade a 550 e 850 m são semelhantes, assim como foi constatado pelas medidas obtidas durante o mapeamento da pluma de dispersão (em 25 de agosto de 2008), mostradas na Figura 6. Além disso, em relação às condições à montante do lançamento, houve aumento de 3 a 36\% (média de 13\%) da condutividade devido ao lançamento do efluente. Outros parâmetros físicos e químicos mostrados na Figura 7 também apresentaram comportamento semelhante ao da condutividade, inclusive óleos e graxas que podem ter um padrão de dispersão diferente das

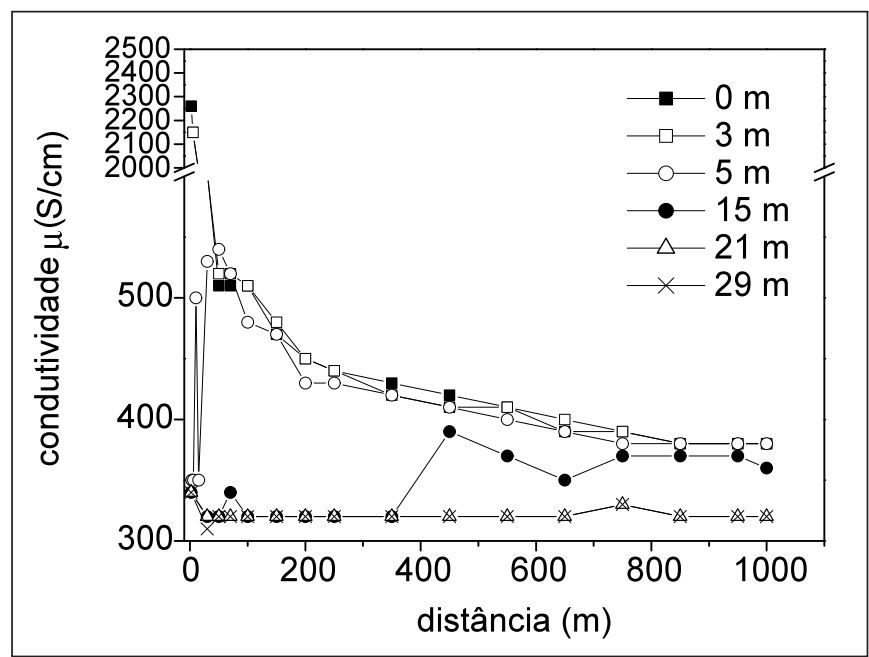

Figura 6 - Medidas de condutividade elétrica no trecho de rio de 1000 $\mathrm{m}$ ao longo de diferentes seções distanciadas de 0 a $29 \mathrm{~m}$ em relação à margem de lançamento 


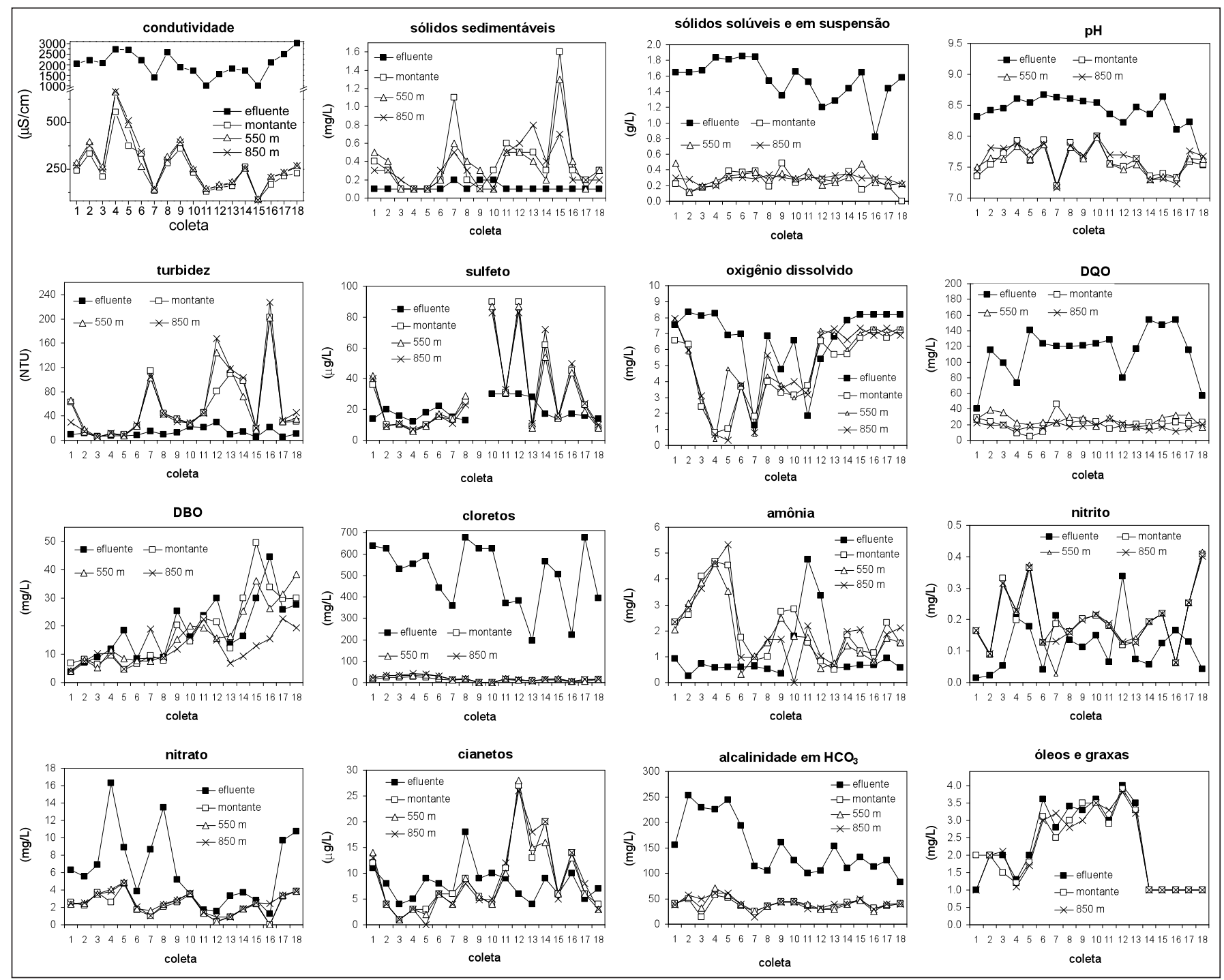

Figura 7 - Medidas de parâmetros físicos e químicos realizadas em 18 coletas quinzenais no período de 01/08/2007 a 28/05/2008 correspondentes à amostragem do efluente e de três pontos no rio localizados à montante $(20 \mathrm{~m})$ do emissário e 550 e $850 \mathrm{~m}$ à jusante

substâncias solúveis. Importante ressaltar que o comportamento semelhante refere-se ao fato de que as concentrações determinadas no primeiro ponto à jusante $(550 \mathrm{~m})$ são semelhantes aos respectivos valores no segundo ponto $(850 \mathrm{~m})$. Contudo, somente uma amostragem em malha, como realizada para a condutividade elétrica, poderia determinar se há alguma correlação espacial entre algum parâmetro físico ou químico (principalmente os conservativos) e a condutividade elétrica.

A Figura 8 mostra a pluma de dispersão do efluente no rio gerada por simulação computacional. Os cálculos para a geração da pluma são baseados principalmente nos dados de vazão, temperatura e concentração do efluente e do rio, bem como nas geometrias do emissário e do rio. Para este último, o simulador considera a geometria de uma calha com base retangular.

A pluma de dispersão gerada pelo simulador apresenta elevada concordância com os dados obtidos em campo. A simulação mostra que a pluma concentra-se na margem do lançamento e esta não atinge a margem oposta, como foi demonstrado com as medidas de condutividade elétrica. De acordo com o simulador, a total homogeneização do efluente ocorreria após 3300 m e, após esse ponto, a condutividade elétrica seria $356 \mu \mathrm{S} / \mathrm{cm}$, o que representaria um aporte de $4,7 \%$. O valor do aporte está dentro da faixa determinada pelas medidas do período estudado. A Figura 9 mostra os valores medidos em campo na margem do lançamento $(0 \mathrm{~m})$ e os valores gerados pela simulação. De acordo com essa comparação, há uma excelente concordância quantitativa entre os dados gerados pelas duas técnicas, principalmente no trecho $200 \mathrm{~m}$ após o lançamento.

Como demonstrado neste trabalho, a simulação computacional pode gerar dados confiáveis e, além disso, pode ser uma ferramenta muito útil para avaliação de diversos cenários, como, por exemplo, condições de baixa vazão do rio ou aumento da carga de efluente, bem como para projeto de emissários. 


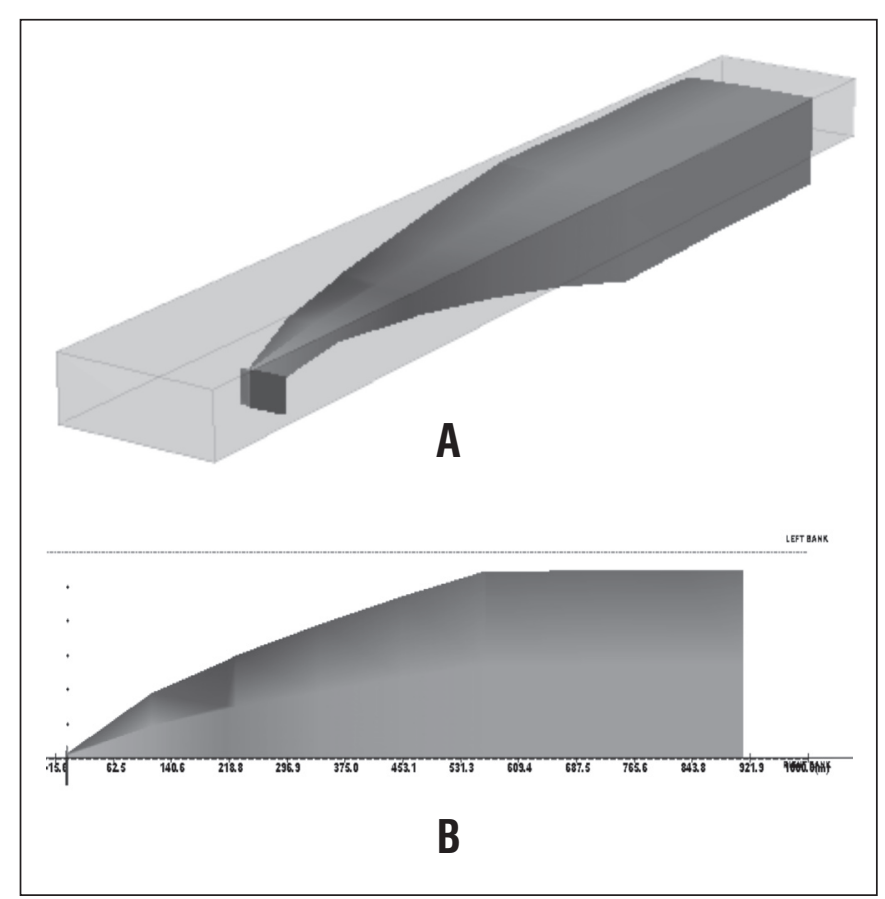

Figura 8 - Pluma de dispersão do efluente da refinaria gerada por simulação computacional. (A) vista 3D; (B) vista em planta

\section{Conclusões}

A medição em campo da condutividade elétrica mostrou-se uma técnica adequada para a avaliação da dispersão de efluentes líquidos de refinaria de petróleo, que apresentam alta condutividade elétrica, e, com isso, há um forte contraste entre os valores do efluente e do rio. As medidas são feitas rapidamente em campo, não havendo a necessidade de transporte de amostras e análises em laboratório, o que economiza tempo e recursos financeiros. Além disso, outros parâmetros de qualidade da água do rio seguiram comportamento de dispersão semelhante ao da condutividade.

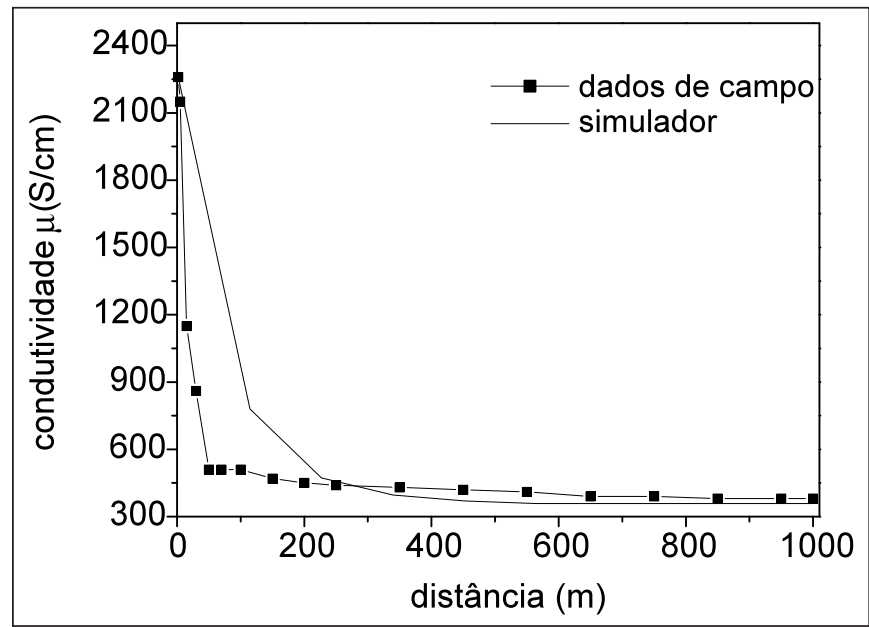

Figura 9 - Comparação entre as medidas de campo na margem do lançamento $(0 \mathrm{~m})$ e os valores gerados pelo simulador computacional

A pluma de dispersão gerada pelo simulador computacional apresentou elevada concordância com os dados obtidos em campo. Nesse sentido, a simulação computacional pode ser uma ferramenta útil e econômica para a avaliação da dispersão do efluente considerando-se cenários hipotéticos, e também para o projeto do emissário.

O conhecimento da pluma de dispersão pode orientar a localização de pontos de coleta para diferentes tipos de análises, uma vez que, em regiões próximas ao emissário, há partes do rio que não estão sob influência do efluente industrial.

\section{Agradecimentos}

Ao Prof. Dr. Daniel Marcos Bonotto (IGCE/Unesp/Rio Claro) por haver gentilmente emprestado o equipamento de medição de condutividade elétrica de campo.

\section{Referências}

ANP (Agência Nacional do Petróleo). Anuário Estatístico Brasileiro do Petróleo, Gás Natural e Biocombustíveis 2008, Seção 2. Disponível em: http://www.anp.gov.br/conheca/ anuario_2008.asp. (2008). Acesso em: 27 mai. 2008.

APHA (American Public Health Association) Standard methods for the examination of water and wastewater. 20. ed. Washington: APHA, AWWA, WPCF, 1998.

BAUD, O. et al. Toward nonintrusive flood discharge measurement. Journal of Hydraulic Engineering, v. 131, n. 12, p. 1031-1035, 2005.

DONEKER, R.L.; Jirka, G.H. CORMIX-Gl systems for mixing zone analysis of brine wastewater disposal. Desalination, v. 139, n. 1-3, p. 263-274, 2001.

DONEKER, R.L.; Jirka, G.H.; Hinton, S.W. A hydrodynamic mixing zone model and decision support system for pollutant discharges into surface waters. Manual do usuário Cormix, 2007.

JONES, G.R. et al. Buoyant surface discharges into water bodies. I: Flow classification and prediction methodology. Journal of Hydraulic
Engineering, v. 133, n. 9, p. 1010-1020, 2007

MACHADO, M.B. Modelagem tridimensional da dispersão de poluentes em rios. Tese (Doutorado) - Faculdade de Engenharia Química da Universidade Estadual de Campinas, Campinas, SP, 2006.

MACHADO, M.B. et al. Software para modelagem de dispersão de efluentes em rios. Engenharia Sanitária e Ambiental, v. 13, n. 3, p. 291 297, 2008

PUN, K-L. Field and model studies of water quality in Hong Kong. In: WOLANSKI, E. (ed.), The Environment in Asia Pacific Harbours. Netherlands: Springer, 2006. p. 165-186.

SANTAELLA, S. T. et al. Tratamento de efluentes de refinaria de petróleo em reatores com Aspergillus niger. Engenharia Sanitaria e Ambiental, v. 14, n. 1, p. 139-148, 2009.

XIA, L.P.; Lam, K.M. Unsteady effluent dispersion in a round jet interacting with an oscillating cross-flow. Journal of Hydraulic Engineering, v. 130, n. 7, p. 667-677, 2004 